\title{
Hypercapnic respiratory failure and partial upper airway obstruction during high frequency oscillatory ventilation in an adult burn patient
}

\author{
[Défaillance respiratoire hypercapnique et obstruction partielle des voies respiratoires \\ supérieures pendant la ventilation oscillatoire à haute fréquence chez un brûlé adulte]
}

Andrew B. Cooper MD FRCP(C), * Avinash Islur BSc, $†$ Manuel Gomez MD MSc, $\ddagger$ Gordon L. Goldenson MD FRCP(C), ${ }^{\star}$ Robert C. Cartotto MD FRCS(C)‡

Purpose: To present a case of severe hypercapnic respiratory failure in an adult burn patient and to describe our clinical problem solving approach during support with an unconventional mode of mechanical ventilation.

Clinical features: A 19-yr-old male with smoke inhalation and flame burns to $50 \%$ total body surface area was admitted to the Ross Tilley Burn Centre. High frequency oscillatory ventilation (HFOV) was initiated on day three for treatment of severe hypoxemia. By day four, the patient met consensus criteria for acute respiratory distress syndrome. On day nine, alveolar ventilation was severely compromised and was characterized by hypercapnea $\left(\mathrm{PaCO}_{2} 136 \mathrm{mmHg}\right)$ and acidosis $(\mathrm{pH}$ 7.10). Attempts to improve $\mathrm{CO}_{2}$ elimination by a decrease in the HFOV oscillatory frequency and an increase in the amplitude pressure failed. An intentional orotracheal tube cuff leak was also ineffective. A 6.0-mm nasotracheal tube was inserted into the supraglottic hypopharynx to palliate presumed expiratory upper airway obstruction. After nasotracheal tube placement, an intentional cuff leak of the orotracheal tube improved ventilation $\left(\mathrm{PaCO}_{2} 81 \mathrm{mmHg}\right.$ ) and relieved the acidosis $(\mathrm{pH}$ 7.30). The improvement in ventilation (with normal oxygen saturation) was sustained until the patient's death from multiple organ dysfunction four days later.

Conclusion: During HFOV in burn patients, postresuscitation edema of the supraglottic upper airway may cause expiratory upper airway obstruction. The insertion of a nasotracheal tube, combined with an intentional orotracheal cuff leak may improve alveolar ventilation during HFOV in such patients.
Objectif : Présenter un cas de défaillance respiratoire hypercapnique sévère chez un grand brûlé adulte et décrire la démarche clinique adoptée pendant l'établissement d'une ventilation mécanique non traditionnelle.

Éléments cliniques : Un homme de 19 ans exposé à des flammes et à l'inhalation de fumée a subi des brûlures sur 50 \% de la surface corporelle et a été pris en charge au Ross Tilley Burn Centre. La ventilation oscillatoire à haute fréquence (VOHF) a été instaurée au troisième jour postopératoire pour traiter une hypoxémie sévère. Au quatrième jour, la condition du patient présentait tous les critères d'un syndrome de détresse respiratoire. Le neuvième jour, la ventilation alvéolaire était sérieusement compromise et caractérisée par de l'hypercapnie $\left(\mathrm{PaCO}_{2}\right.$ $136 \mathrm{mmHg}$ ) et de l'acidose $(\mathrm{pH} 7,10)$. Les tentatives pour améliorer l'élimination du $\mathrm{CO}_{2}$ en diminuant la fréquence oscillatoire de la VOHF et en augmentant la pression d'amplitude ont échoué. Une fuite provoquée volontairement dans le ballonnet du tube orotrachéal a été aussi inefficace. Un tube nasotrachéal de 6,0 mm a été inséré dans l'hypopharynx supraglottique pour pallier l'obstruction présumée des voies respiratoires supérieures. Après la mise en place du tube nasotrachéal, une fuite intentionnelle du ballonnet du tube orotrachéal a amélioré la ventilation $\left(\mathrm{PaCO}_{2} 81 \mathrm{mmHg}\right)$ et fait disparaitre l'acidose ( $\left.\mathrm{pH} 7,30\right)$. L'amélioration de la ventilation (avec une saturation normale en oxygène) a été maintenue jusqu'au décès du patient, quelques jours plus tard à la suite d'une défaillance multiviscérale.

Conclusion : Pendant la VOHF chez des grands brûlés, l'œdème des voies respiratoires supraglottiques en période postranimation peut causer une obstruction des voies respiratoires supérieures. L'insertion d'un tube nasotrachéal, combinée à une fuite provoquée du ballonnet orotrachéal, peut améliorer la ventilation alvéolaire pendant la VOHF chez ces patients.

From the Departments of Anesthesia and Critical Care, ${ }^{*}$ and Surgery, $\dagger$ Sunnybrook and Women's College Health Sciences Centre, and the Department of Surgery, $\ddagger$ Ross Tilley Burn Centre, Toronto, Ontario, Canada.

Address correspondence to: Dr. Robert Cartotto, Ross Tilley Burn Centre, Sunnybrook and Women's College Hospital, Room D712, 2075 Bayview Avenue, Toronto, Ontario M4N 3M5, Canada. Phone: 416-480-6706; Fax: 416-480-6708;

E-mail: Robert.Cartotto@swchsc.on.ca

Supported by the Department of Anesthesia, Sunnybrook and Women's College Health Sciences Centre.

Accepted for publication January 14, 2002

Revision accepted May 13, 2002. 


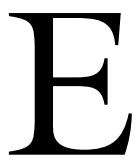

VOLVING basic science ${ }^{\mathrm{l}}$ and human clinical trial evidence support the use of mechanical ventilation strategies whose goal is the prevention of ventilator associated lung injury due to alveolar overdistension and endexpiratory alveolar collapse in acute respiratory distress syndrome (ARDS). Lung protective ventilation strategies have been shown to improve survival in patients with ARDS in prospective randomized controlled trials. ${ }^{2,3}$ In addition, it is possible that such strategies may reduce systemic inflammation and protect against the development of multiple organ dysfunction (MOD) syndrome in these patients. ${ }^{4}$ High frequency oscillatory ventilation (HFOV) may accomplish the goals of a lung protective ventilation strategy better than conventional ventilation because sustained mean airway pressures can be applied to achieve and maintain lung recruitment while avoiding prolonged over-distending peak pressures.

While it has become commonplace to adopt a lung protective ventilation approach to patients with thermal and inhalation injury, clinical experience with HFOV in adult burn patients is not well documented in the literature. Evidence in this population is limited to improvements in oxygenation in small case series of adult burn patients. ${ }^{5,6}$ Complications associated with HFOV in the above studies included hypotension, barotrauma (pneumothorax, pneumomediastinum), desiccation of secretions and equipment failure. While alveolar hypoventilation (hypercapnic respiratory failure) may occur during initial management of $\mathrm{HFOV}^{7}$ carbon dioxide elimination has been found to be superior compared to conventional ventilation. ${ }^{5}$ We present an adult burn patient in whom, to the contrary, severe alveolar hypoventilation was encountered and we discuss our management of this unusual clinical problem.

\section{Case report}

A 19-yr-old man was transferred to the Ross Tilley Burn Centre six hours after a motor vehicle crash and fire. The patient was intubated in the referring hospital with a 7.0 cut oral endotracheal tube. Primary and secondary trauma evaluation including plain radiographs revealed only a small left-sided pneumothorax in addition to the patient's burn injury. A chest drain was required. The patient's burn injury involved 50\% of total body surface area (TBSA). There were burns of the head and neck, both upper extremities, the trunk, and the left leg. Smoke inhalation injury was diagnosed based on his history of injury in a closed space fire and bronchoscopic findings. On the first day after admission, the patient was taken to the operating room for a tracheostomy to secure the airway, which had become tenuous owing to the patient's facial edema and the inadequate length of the endotracheal tube. An 8.0 adjustable flange tracheostomy tube was inserted. The patient's initial $24 \mathrm{hr}$ resuscitation volume exceeded the Parkland Formula prediction by $75 \%$ ( $7 \mathrm{~mL} \cdot \mathrm{kg}^{-1} / \%$ TBSA burn $)$, reflecting the effect of the inhalation injury.

On day three at 07:00, pressure control ventilation (PCV) settings were peak inflation pressure (PIP) 34 $\mathrm{cm} \mathrm{H}_{2} \mathrm{O}$, PEEP $10 \mathrm{~cm} \mathrm{H}_{2} \mathrm{O}$, tidal volume $540 \mathrm{~mL}$, rate $18 \mathrm{~min}^{-1}$ with a $\mathrm{PaO}_{2} / \mathrm{F}_{\mathrm{I}} \mathrm{O}_{2}$ ratio of 103 . The chest $x$ ray showed mild interstitial pulmonary edema, pleural fluid tracking superiorly and left lower lobe atelectasis. At 12:00 hr, HFOV was initiated to improve oxygenation within the context of evolving hypoxemic respiratory failure. HFOV settings were $\mathrm{F}_{\mathrm{I}} \mathrm{O}_{2}$ 1.0, mean airway pressure $35 \mathrm{~cm} \mathrm{H}_{2} \mathrm{O}$, frequency $4 \mathrm{~Hz}$, I: E $33 \%$. Amplitude was set to obtain oscillations to mid-thigh level. The patient subsequently underwent staged excision and grafting of his burn wounds. On day four the patient's hypoxemia, bilateral airspace consolidation and the lack of evidence for congestive heart failure satisfied consensus criteria for ARDS. ${ }^{8}$

On day five the patient had developed abdominal compartment syndrome, manifested by worsening oliguria, and intra-abdominal pressures $>30 \mathrm{mmHg}$ by bladder transduction, and was taken urgently to the operating room for a decompressive laparotomy. Following laparotomy, there was no further evidence of abdominal hypertension based on daily measurements of intra-abdominal pressure by bladder transduction.

On day seven, operative debridement and temporary allografting of the face and neck was performed. On arrival in the operating room the patient became impossible to ventilate due to an apparent obstruction of the tracheostomy tube. Fibreoptic endoscopy did not disclose the cause of the obstruction. The patient was orally re-intubated with an 8.0 oral endotracheal tube by the anesthesiologist. Postoperatively the patient developed hypercapnic ventilatory failure and at 21:00 hr ventilation was briefly changed to PCV mode. With PIP $48 \mathrm{~cm} \mathrm{H}_{2} \mathrm{O}$, PEEP $20 \mathrm{~cm} \mathrm{H}_{2} \mathrm{O}$, tidal volume $800 \mathrm{~mL}$ and rate $16 \mathrm{~min}^{-1}$ the arterial blood gases were $\mathrm{pH} 7.23 \mathrm{pCO}_{2} 68 \mathrm{pO}_{2} 145 \mathrm{HCO}_{3}^{-} 29$. The patient's subsequent ventilation and oxygenation course are presented in graphic form in Figure 1.

The following morning, (day eight), at 10:00 hr $\mathrm{HFOV}$ was re-instituted. Oscillator settings were $\mathrm{F}_{\mathrm{I}} \mathrm{O}_{2}$ 1.0 , mean airway pressure $41 \mathrm{~cm} \mathrm{H}_{2} \mathrm{O}$, I: E $33 \%$. Amplitude was set as before to obtain oscillations to mid-thigh level. The HFOV frequency was decreased to $3 \mathrm{~Hz}$ in an attempt to improve $\mathrm{CO}_{2}$ elimination; however alveolar hypoventilation persisted; $\mathrm{pH} 7.17$ 


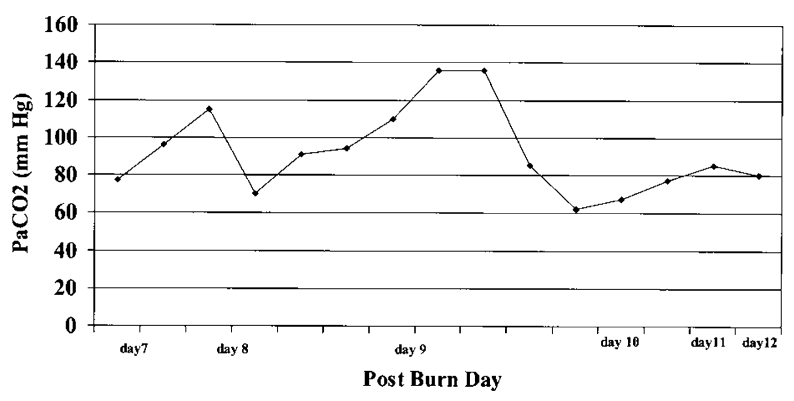

FIGURE 1 Changes in $\mathrm{PaCO}_{2}$ over time on postburn days seven to 12 .

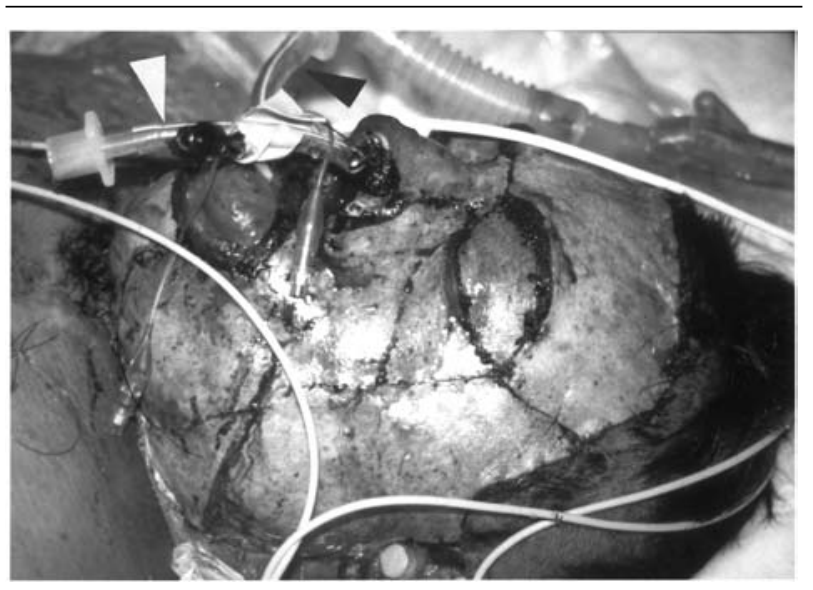

FIGURE 2 Simultaneous placement of an oral endotracheal tube (black arrowhead) attached to the ventilator circuit, and a nasal endotracheal tube (white arrowhead) as a supraglottic vent. Note the profound facial and tongue edema.

$\mathrm{pCO}_{2} 78 \mathrm{pO}_{2} 160 \mathrm{HCO}_{3}^{-} 29$. An intentional leak of the endotracheal tube cuff was induced, by reducing pressure in the pilot balloon. Bias flow on the oscillator was increased to $50 \mathrm{~L} \cdot \mathrm{min}^{-1}$ (the maximum) to maintain mean airway pressure. This maneuver was ineffective and $\mathrm{CO}_{2}$ elimination actually worsened. At 16:00 hr, blood gases were $\mathrm{pH} 7.09, \mathrm{pCO}_{2} 98, \mathrm{pO}_{2}$ $163, \mathrm{HCO}_{3}-30, \mathrm{PaO}_{2} / \mathrm{F}_{\mathrm{I}} \mathrm{O}_{2}$ ratio 163 . By 22:00 hr, the patient showed evidence of alveolar de-recruitment in that oxygenation worsened despite a mild improvement in $\mathrm{CO}_{2}$ elimination $\left(\mathrm{pH} 7.18 \mathrm{pCO}_{2} 83\right.$ $\mathrm{pO}_{2} 71 \mathrm{HCO}_{3}^{-} 32, \mathrm{PaO}_{2} / \mathrm{F}_{\mathrm{I}} \mathrm{O}_{2}$ ratio 128 ).

Hypercapnic ventilatory failure continued on day nine. The endotracheal tube cuff leak was sealed because of concerns about oxygenation. This resulted in a zenith of hypoventilation at 18:00 hr, while oscilla- tor settings were $\mathrm{F}_{\mathrm{I}} \mathrm{O}_{2} 1.0$, mean airway pressure $48 \mathrm{~cm}$ $\mathrm{H}_{2} \mathrm{O}$, frequency $3 \mathrm{~Hz}$, I: $\mathrm{E} 33 \%$, with $\Delta \mathrm{P}$ power set as before. Blood gases then were $\mathrm{pH} 7.10 \mathrm{pCO}_{2} 136 \mathrm{pO}_{2}$ $139 \mathrm{HCO}_{3}-44, \mathrm{PaO}_{2} / \mathrm{F}_{\mathrm{I}} \mathrm{O}_{2}$ ratio 278. After much reflection, we entertained the possibility that massive edema of the upper airway might have prevented egress of $\mathrm{CO}_{2}$ after initiation of the endotracheal tube cuff leak. To create an effective upper airway, a 6.0 endotracheal tube was gently inserted through the left naris into the hypopharynx (Figure 2). The orotracheal cuff leak was re-instituted at 21:00 hr. There was free gas flow through the lumen of the nasotracheal tube and a change in the pitch of the oscillation of the ventilator diaphragm was noted. $\mathrm{CO}_{2}$ elimination immediately and dramatically improved; at 22:00 pH 7.30 $\mathrm{pCO}_{2} 85$ $\mathrm{pO}_{2} 82 \mathrm{HCO}_{3}-42, \mathrm{PaO}_{2} / \mathrm{F}_{\mathrm{I}} \mathrm{O}_{2}$ ratio 170 . The improvement in alveolar ventilation persisted until the patient's death (Figure 1).

By day 12, despite successful excision and autograft closure of the patient's burn wounds, sepsis persisted with worsening MOD. The MOD score $^{9}$ was 12 , which corresponds to an observed mortality of $30 \%$ in our burn patients, when corrected for severity of skin injury. ${ }^{10}$ Blood cultures drawn on day ten were positive for pseudomonas aeruginosa. The patient developed refractory septic shock despite cardiovascular support with epinephrine, norepinephrine and vasopressin. After consultation with the patient's family, a decision was made to provide only comfort measures. The patient died immediately after withdrawal of cardiovascular support.

\section{Discussion}

HFOV is a unique form of high frequency ventilation in which an oscillatory diaphragm produces both active inspiration and active expiration of small, sub-deadspace tidal volumes at frequencies up to $15 \mathrm{~Hz} .{ }^{11}$ Continuous airflow ("bias flow") of 20-40 L.min ${ }^{-1}$ creates a sustained mean airway pressure $\left(\mathrm{P}_{\text {mean }}\right)$ which recruits and retains open alveoli. Therefore, manipulation of the $\mathrm{P}_{\text {mean }}$ directly affects oxygenation. The amplitude pressure $(\Delta \mathrm{P})$ is centered over the $\mathrm{P}_{\operatorname{mean}}$ and oscillates above and below the $\mathrm{P}_{\text {mean }}$ with each short breath. Thus, the $\mathrm{P}_{\text {mean }}$ is only exceeded by $\Delta \mathrm{P} / 2$ at the peak of each brief inspiratory phase. However, it is estimated that only $10 \%$ of the $\Delta \mathrm{P} / 2$ is transmitted to the alveoli. ${ }^{11}$ Hence, during HFOV, alveolar recruitment is achieved with sustained mean airway pressures, while avoiding significant or prolonged over-distending peak pressures. During HFOV, expiration is active and $\mathrm{CO}_{2}$ elimination is manipulated by adjusting the oscillatory frequency, and the $\Delta \mathrm{P}$. At the bedside, the initial $\Delta \mathrm{P}$ is empirically adjusted so that the chest wall vibrations are 
transmitted as far as the mid-thigh, to create thigh "wiggle". 5 This usually correlates with a $\Delta \mathrm{P}$ that is adequate for effective $\mathrm{CO}_{2}$ removal. However, the $\Delta \mathrm{P}$ may need to be adjusted thereafter based on the $\mathrm{P}_{\mathrm{a}} \mathrm{CO}_{2}$.

We describe an adult patient with cutaneous burns and ARDS in whom a reduction in HFOV frequency setting to $3 \mathrm{~Hz}$ (with adequate oscillatory amplitude) failed to improve alveolar ventilation. A common practice when this measure fails is to create an intentional cuff leak in the oral endotracheal tube. This usually improves $\mathrm{CO}_{2}$ elimination and is recommend-

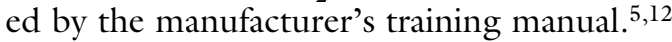

When the change in HFOV settings and an intentional cuff leak failed to improve ventilation, we first satisfied ourselves that there was no malfunction of the ventilator circuit or endotracheal tube. It was acknowledged that the patient's burn could be expected to result in increased carbon dioxide production. However, the deterioration occurred acutely and minute ventilation had previously been adequate which suggested that an acute increase in carbon dioxide production was unlikely to be the cause of the problem. The smoke inhalation injury he sustained had previously resulted in clinically minor alveolar hypoventilation, without an excessive volume of secretions from the lower airway. There was no evidence of lower airway obstruction clinically, and chest $x$-rays did not show hyperinflation consistent with gas trapping. The possibility of an acute increase in physiological deadspace resulting from pulmonary embolism was considered. However, a concurrent deterioration in oxygenation had not occurred and the patient remained hemodynamically stable. The patient had received prophylactic anticoagulation with subcutaneous heparin since admission. He was judged to have an intermediate probability (20-79\%) of pulmonary embolism based on clinical criteria. ${ }^{13}$ Because of the risk involved in transporting the patient to the computed tomography (CT) suite in his unstable condition, a decision was made to investigate pulmonary embolism with CT angiography only if measures to improve ventilation failed to be effective. Systemic anticoagulation with therapeutic-dose heparin was considered inadvisable in view of the patient's risk factors for surgical bleeding.

Carbon dioxide elimination during HFOV was studied extensively in animal models during the 1980's. During HFOV $\mathrm{CO}_{2}$ excretion is essentially independent of lung volume above functional residual capacity, up to high transpulmonary pressures. ${ }^{14}$ Log log plots show that arterial $\mathrm{PCO}_{2}$ decreases linearly as a function of the product of frequency and the square of tidal volume. Carbon dioxide transport during
HFOV depends on an inefficient diffusion mechanism, dependent on frequency and tidal volume, and a more efficient convective mechanism that is dependent on tidal volume. ${ }^{15}$ At the bedside, improved alveolar ventilation is achieved by increasing the amplitude and reducing the frequency. ${ }^{16}$ The common clinical observation of improved $\mathrm{CO}_{2}$ elimination with a reduction in oscillatory frequency probably results from reduced impedance and increased tidal volume as oscillation approaches the natural frequency of the patient's respiratory system (Slutsky A, personal communication). There had been no observed decrease in our patient's oscillatory amplitude at the time of the ventilatory crisis. In contrast to conventional ventilation modes, alterations in the ratio of inspiratory to expiratory time have little effect on carbon dioxide elimination during $\mathrm{HFOV} .^{17}$

Physical examination of the patient during the crisis was revelatory. The patient was in supine position, and the chest was oscillating freely. Oscillations could also be seen to mid-thigh level. Auscultation of the chest was positive only for the expected transmitted sounds of the ventilator's oscillating diaphragm. Severe edema of the visible upper airway (nose, tongue, and lips) was associated with an increased neck circumference (Figure 2). These features of the patient's condition together with alveolar hypoventilation crisis suggested an analogy with the obstructive sleep apnea syndrome (OSAS). Increased neck circumference in OSAS is highly correlated with patient symptoms and objective evidence of sleep-disordered breathing. ${ }^{18}$ Magnetic resonance imaging studies of the upper airway anatomy of patients with OSAS have demonstrated thickened lateral pharyngeal walls as the substrate for upper airway obstruction. ${ }^{19}$ Nocturnal noninvasive ventilation (bilevel positive airway pressure) improves alveolar ventilation by stenting the obstructed upper airway, thereby increasing airway caliber. ${ }^{20}$ Although occurring in a very different clinical setting from OSAS, upper airway obstruction due to edema was a probable cause for the failure of an intentional endotracheal tube cuff leak to improve our patient's alveolar ventilation during HFOV. The immediate and sustained improvement in carbon dioxide elimination $\left(\mathrm{PaCO}_{2} \quad 136-85 \mathrm{mmHg}\right)$ that occurred after insertion of a nasopharyngeal airway, we believe, is consistent with this mechanism of ventilatory failure.

In summary, we feel this case emphasizes important principles of ventilator management that are applicable to any patient, regardless of mode of mechanical ventilation. During an acute ventilatory crisis it is important to ensure adequacy of the airway and to 
exclude technical failure of the mechanical ventilator. A thorough and systematic review of the physiology of the acute problem with consideration of the impact of the patient's unique pathophysiology may suggest an intervention. In the case presented, the unusual problem of expiratory upper airway obstruction during HFOV was identified and successfully treated by following the steps described.

\section{References}

1 Dreyfuss D, Saumon G. Ventilator-induced lung injury: lessons from experimental studies. Am J Respir Crit Care Med 1998; 157: 294-323.

2 The Acute Respiratory Distress Syndrome Network. Ventilation with lower tidal volumes as compared with traditional tidal volumes for acute lung injury and the acute respiratory distress syndrome. N Engl J Med 2000; 342: 1301-8.

3 Amato MBP, Barbas CSV, Medeiros DM, et al. Effect of a protective-ventilation strategy on mortality in the acute respiratory distress syndrome. $\mathrm{N}$ Engl J Med 1998; 338: 347-54.

4 Ranieri VM, Suter PM, Tortorella C, et al. Effect of mechanical ventilation on inflammatory mediators in patients with acute respiratory distress syndrome. A randomized controlled trial. JAMA 1999; 282: 54-61.

5 Mehta S, Lapinsky SE, Hallett DC, et al. Prospective trial of high-frequency oscillation in adults with acute respiratory distress syndrome. Crit Care Med 2001; 29: 1360-9.

6 Cartotto R, Cooper AB, Esmond JR, Gomez M, Fish JS, Smith $T$. Early clinical experience with high- frequency oscillatory ventilation for ARDS in adult burn patients. J Burn Care Rehabil 2001; 22: 325-33.

7 Fort P, Farmer C, Westerman J, et al. High-frequency oscillatory ventilation for adult respiratory distress syndrome - a pilot study. Crit Care Med 1997; 25: 937-47.

8 Bernard GR, Artigas A, Brigham KL, et al., and the Consensus Committee. The American-European consensus conference on ARDS. Definitions, mechanisms, relevant outcomes, and clinical trial coordination. Am J Resp Crit Care Med 1994; 149: 818-24.

9 Marshall JC, Cook DJ, Christou NV, Bernard GR, Sprung CL, Sibbald WJ. Multiple organ dysfunction score: a reliable descriptor of a complex clinical outcome. Crit Care Med 1995; 23: 1638-52.

10 Innes M, Cartotto RC, Cooper AB, Fish JS, Gomez, $M$. The multiple organ dysfunction score (MODS) in burn patients. J Burn Care Rehabil 2001; 22: 109.

11 Brambrink AM, Brachlow J, Weiler N, et al. Successful treatment of a patient with ARDS after pneumonectomy using high-frequency oscillatory ventilation.
Intensive Care Med 1999; 25: 1173-6.

12 3100A High Frequency Oscillatory Ventilator Training Manual. 1997.

13 Hyers TM. Venous thromboembolism. Am J Respir Crit Care Med 1999; 159: 1-14.

14 Slutsky AS, Kamm RD, Rossing TH, et al. Effects of frequency, tidal volume, and lung volume on $\mathrm{CO}_{2}$ elimination in dogs by high frequency $(2-30 \mathrm{~Hz})$, low tidal volume ventilation. J Clin Invest $1981 ; 68$ : 1475-84.

15 Boynton BR, Hammond MD, Fredberg JJ, Buckley BG, Villanueva D, Frantz ID 3rd. Gas exchange in healthy rabbits during high-frequency oscillatory ventilation. J Appl Physiol 1989; 66: 1343-51.

16 Morgan C, Dear PR, Newell SJ. Effect of changes in oscillatory amplitude on $\mathrm{PaCO}_{2}$ and $\mathrm{PaO}_{2}$ during high frequency oscillatory ventilation. Arch Dis Child Fetal Neonatal Ed 2000; 82: F237-F42.

17 Venegas JG, Yamada $\Upsilon$, Custer J, Hales CA. Effects of respiratory variables on regional gas transport during high-frequency ventilation. J Appl Physiol 1988; 64: 2108-18.

18 Flemons WW, Whitelaw WA, Brant R, Remmers JE. Likelihood ratios for a sleep apnea clinical prediction rule. Am J Respir Crit Care Med 1994; 150: 1279-85.

19 Schwab RJ, Gupta KB, Gefter WB, Metzger LJ, Hoffman EA, Pack AI. Upper airway and soft tissue anatomy in normal subjects and patients with sleep-disordered breathing. Significance of the lateral pharyngeal walls. Am J Respir Crit Care Med 1995; 152: 1673-89.

20 Schwab RJ, Pack AI, Gupta KB, et al. Upper airway and soft tissue structural changes induced by CPAP in normal subjects. Am J Respir Crit Care Med 1996; 154: 1106-16. 